\title{
O Mundo das Mídias Sociais Segundo os Brasileiros: uma análise da presença das mídias sociais em um programa de infotenimento
}

Carlos Eduardo dos Reis

\begin{abstract}
Resumo: Este artigo efetua uma análise da influência das mídias sociais na produção do programa de TV O Mundo Segundo os Brasileiros (Brasil, TV Bandeirantes). Esta produção pertencente ao gênero infotenimento, retrata a cultura de uma determinada cidade do ponto de vista de um grupo de brasileiros, de idades e perfis diferentes, que mostram para as câmeras como vivem naquele ambiente. $O$ termo infotenimento deriva da junção entre as palavras informação e entretenimento e é visto cada vez mais nas produções televisivas. Analisamos as mídias sociais (Facebook/Fanpage, Twitter e Instagram) oficiais do programa e percebemos que além da divulgação dos episódios, o processo de recrutamento dos participantes é iniciado por esse meio. $O$ surgimento das novas tecnologias abre novas perspectivas de interação entre produtor e as novas plataformas contribuem para o desenvolvimento do produto, já que os produtores passam a compreender melhor 0 desejo do mercado. Este estudo é relevante, pois parece ser uma tendência das empresas de comunicação utilizarem cada vez mais as mídias sociais para se relacionarem com o seu público-alvo.
\end{abstract}

Palavras-chave: Infotenimento, mídia social, audiovisual, comunicação.

Abstract: This article effectuate an analysis of the influence of social media on the production of the TV program O Mundo Segundo os Brasileiros (Brazil, TV Bandeirantes). This production belongs to the genre infotainnment, portrays the culture of a certain city from the point of view of a group of Brazilians, of different ages and profiles, who show the cameras how they live in that environment. The term infotainnment comes from the junction between the words information and entertainment and is seen more and more in television productions. We analyze the official social media (Facebook / Fanpage, Twitter and Instagram) of the program and realize that besides the divulgation of the episodes, the process of recruiting the participants is initiated by this means. The emergence of new technologies opens new perspectives of producer-consumer interaction and the new platforms contribute to the development of the product, as producers begin to better understand the desire of the market. This study is relevant because it seems to be a tendency of communication companies to increasingly use social media to relate to their target audience.

Keywords: Infotainment, social media, audiovisual, communication. 
Resumen: Este artículo efectúa un análisis de la influencia de los medios sociales en la producción del programa de televisión O Mundo Segundo os Brasileiros (Brasil, TV Bandeirantes). Esta producción perteneciente al género infotenimiento, retrata la cultura de una determinada ciudad desde el punto de vista de un grupo de brasileños, de edades y perfiles diferentes, que muestran para las cámaras como viven en aquel ambiente. El término infotenimiento deriva de la unión entre las palabras información y entretenimiento y se ve cada vez más en las producciones televisivas. Se analizan los medios sociales (Facebook / Fanpage, Twitter e Instagram) oficiales del programa y percibimos que además de la divulgación de los episodios, el proceso de reclutamiento de los participantes es iniciado por ese medio. El surgimiento de las nuevas tecnologías abre nuevas perspectivas de interacción entre productor y consumidor y las nuevas plataformas contribuyen al desarrollo del producto, ya que los productores comprenden mejor el deseo del mercado. Este estudio es relevante, pues parece ser una tendencia de las empresas de comunicación utilizar cada vez más los medios sociales para relacionarse con su público objetivo.

Palabras clave: Infotenimiento, medios sociales, audiovisual, comunicación.

\section{Introdução}

Neste artigo, analisamos o programa de TV O Mundo Segundo os Brasileiros, buscando compreender a influência que as mídias sociais exercem sobre uma atração de infotenimento. O Mundo Segundo os Brasileiros é uma produção adaptada do formato argentino Clase Turista: el mundo según los argentinos. Produzido pela produtora de origem holandesa Eyeworks; a edição brasileira é transmitida pela TV Bandeirantes desde 2011. Outros países como Chile, México, Espanha e Portugal também possuem versões desse programa.

o Mundo Segundo os Brasileiros retrata um grupo de imigrantes que apresenta para o telespectador os pontos históricos e culturais da cidade documentada, e principalmente demonstra como vivem e se relacionam naquela cultura. Diferentemente de um programa de turismo que se preocupa somente em mostrar as principais atrações locais, O Mundo Segundo os Brasileiros apresenta lugares bastante peculiares que somente quem faz parte daquele cotidiano saberia demonstrar. Por revelar informações históricas e contemporâneas e, sobretudo, relevantes para quem tem interesse em se aprofundar na cultura da cidade apresentada, podemos afirmar que esse programa é do gênero infotenimento.

O objetivo principal de qualquer produção televisiva é a audiência. Uma boa audiência gera recursos econômicos para a TV, aliás, o principal objetivo de qualquer empresa capitalista Para atrair mais público e ganhar da concorrência, as emissoras estão deixando os programas menos densos, equilibrando o conteúdo jornalístico com a leveza do entretenimento. Esse processo evoluiu e está cada vez mais presente nos gêneros. Um gênero que mistura informação com diversão está tomando conta da grade de programação dos grandes grupos midiáticos. É a era das produções de infotenimento. Como o próprio nome diz, a palavra infotenimento vem da junção entre as palavras informação e entretenimento. Esse tipo de conteúdo percorre a linha tênue entre a seriedade e o divertimento, tornando-o mais atraente para o receptor. Para Martino (2009, p. 155) o infotenimento é "articulação estética para tornar informações reais agradáveis e fáceis de serem compreendidas ou mesmo borrar a fronteira entre informação e entretenimento passando mensagens sérias ao lado de atrações 
mais leves". Umas das características desse gênero é a interação com o público-alvo. As transformações tecnológicas proporcionam ao público mais acesso aos conteúdos e a possibilidade de interagir com a produção, e essa, por sua vez adapta o formato de acordo com a vontade do público. Dejavite (2006) afirma que depois dos anos 1980, a mídia se readequou às novas tecnologias:

Durante a década de 1980, a mídia passou por uma das mais profundas transformações proporcionadas pelas novas tecnologias. Em meados da década seguinte, o aparecimento das novas tecnologias de comunicação - em especial o da internet (a espinha dorsal tecnológica que constitui e organiza essa nova era) - veio reestruturar as formas de como produzimos, distribuímos e recebemos as informações. (DEJAVITE, 2006, p. 14)

Ao percorrer um caminho no qual a informação e o entretenimento se cruzam, os produtores têm o desafio de não abusar da dramatização e do sensacionalismo. Rangel (2010, p. 3) se preocupa com esse tipo de gênero e afirma que "na contemporaneidade, a informação deixa de significar a representação simbólica dos fatos para se apresentar como produto híbrido que se associa ora à publicidade, ora ao entretenimento, ora ao consumo; por vezes ela deixa de cumprir a missão primordial de informar". Dejavite (2006, p. 95) diz que "o que realmente diferencia uma e outra (a matéria séria da não séria) é menos o conteúdo e mais a forma de veicular a informação". Dejavite (2007, p. 2) esclarece que "tal termo [infotenimento] surgido durante a década de 1980, só ganhou força no final dos anos de 1990, quando passou a ser empregado por profissionais e acadêmicos da área comunicacional".

É possível identificar a presença do infotenimento em todas as editorias, como bem entende Sacramento (2014, p. 188): "[...] Especialidades voltadas ao entretenimento, mas que também informam como artes, beleza, cinema, cultura, música, turismo, entre outros, são considerados, também como sendo da categoria de infotenimento". O infotenimento traduz as mudanças socioculturais que atravessam a contemporaneidade, resultando na busca da liderança de mercado, e em muitos casos manipulando o conteúdo para atender à demanda capitalista. De acordo com Gomes (2009, p. 209 -210):

O infotainment parece ser o resultado de uma complexa articulação entre políticas macroeconômicas, marcos regulatórios, possibilidades tecnológicas, estratégias empresariais, expectativas históricas e culturais sobre os sistemas televisivos e seus produtos, ideologias, práticas e expectativas profissionais do campo midiático, pressupostos e conhecimentos sobre a audiência.

É nítido que esse gênero surgiu estrategicamente com o objetivo de alavancar as audiências, pois nos parece que contar uma história séria através de uma narrativa menos densa pode atingir mais telespectadores. Sem a preocupação em seguir um roteiro jornalístico, Gomes (2009, p. 204) acredita que o "[...] infotainment designa uma das principais estratégias comunicativas, aquela que se traduz por contar uma história que seja suficientemente excitante ou dramática para atrair telespectadores". O Mundo Segundo os Brasilleiros é só um dos vários programas desse tipo de gênero que chegou à grade da TV Bandeirantes. Cada vez mais a emissora paulista tende a ir por esse caminho. Sacramento (2014) acredita que esse caminho pode, de fato, atrair mais público. Para o autor, 
[...] Ao surgir a fusão do entretenimento ligada aos programas informativos, como os de jornalismo, observa-se a veiculação de matérias leves que se mesclavam aos fatos mais sérios na intenção de atrair uma parcela maior de público, diversificando o leque de audiência. (SACRAMENTO, 2014, p. 188)

A TV Bandeirantes exibiu no dia 04 de janeiro de 2011, o primeiro episódio de O Mundo Segundo os Brasileiros, retratando a cidade de Jerusalém. A primeira temporada da versão brasileira teve dez episódios e foi produzida na Argentina com a equipe alocada na sede da Eyeworks-Cuatro Cabezas em Buenos Aires. Entre a exibição da primeira e da segunda temporada houve um hiato de quase dez meses. A produção da segunda temporada passou a ser realizada em São Paulo e o programa retomou a grade de programação no dia 02 de janeiro de 2012 com o episódio de Miami. Em 2016, foi ao ar a sexta temporada e a sétima em 2017.

Foi em 2008 que a Eyeworks-Cuatro Cabezas resolveu investir no mercado brasileiro, através de uma parceria com a TV Bandeirantes. O programa CQC - Custe o Que Custar, baseado no original argentino CQC - Caiga Quien Caiga, estreava na grade da emissora paulista. 0 programa ficou no ar até o final de 2015 e teve a promessa de retornar à grade da Band entre o segundo semestre de 2017 e o primeiro de 2018, mas até o momento não se concretizou. Foi o primeiro de muitos programas oriundos dessa parceria.

A parceria entre a Band e a produtora Eyeworks tem a necessidade de produzir conteúdo de qualidade, e, acima de tudo, rentável para a empresa. Esse tipo de negócio é bom para ambas. A produtora vende o seu produto para uma emissora de representatividade nacional e obtém retorno financeiro. Já a Band compra o formato por um custo menor do que se fosse produzir o programa, e assim, utiliza a técnica e a tecnologia da Eyeworks para preencher a grade de programação. A diminuição dos custos e a busca pelo conhecimento de terceiros justificam a associação a uma produtora independente. Tanto o conhecimento técnico quanto a disposição tecnológica caminham juntos, embora possuam conceitos diferentes, como afirma Pinto (2005, 2005, p. 219):

[... "tecnologia" equivale pura e simplesmente a técnica. Indiscutivelmente constitui este o sentido mais frequente e popular da palavra, o usado na linguagem corrente, quando não se exige precisão maior. As duas palavras mostram-se, assim, intercambiáveis no discurso habitual, coloquial e sem rigor.

Depois do CQC, a Eyeworks produziu para a Band o E24 ou Emergência 24 horas, que foi ao ar até 2012, e em seguida o Polícia 24 horas, ainda presente na grade de programação. Assim como o Mundo Segundo os Brasileiros, A Liga estreou na Band, em 2011, e desde então o programa não saiu mais da programação do canal paulista. Outros programas que a Eyeworks produziu para a Band e já foram encerrados: Conversa de Gente Grande (2012); Mulheres Ricas (2012 até 2013); O Formigueiro (2010); Perdidos na Tribo(2012); Quem Quer Casar com Meu Filho?(2014) e Sabe ou Não Sabe(2014).

Nos anos de 2014 e 2015, a Band exibiu o MasterChef, mas em 2016 a Eyeworks cedeu a produção para a Endemol, outra produtora holandesa, que é mais conhecida pelo reality show Big Brother, e o programa continuou na programação da emissora paulista. A parceria Eyeworks-Band continua e está sendo produzido para os próximos meses o programa Era Uma Vez Uma História. Além dessa parceria, a Eyeworks também trabalha com outras emissoras na produção de conteúdo: Coletivation (MTV/2013); História Secreta (History Channel/2010); Mudar Faz Bem (Discovery Home \& Health/2010); Plantão do Tas (Cartoon 
Network/2009 até a presente data); Programa do Porchat (Rede Record/2016 até a presente data). Os formatos da Eyeworks chamaram a atenção da Warner Bros. Television Group. Em fevereiro de 2014, de acordo com a agência de notícias, PR Newswire², este conglomerado midiático estadunidense adquiriu todas as empresas da Eyeworks fora dos Estados Unidos, espalhadas na Europa, América do Sul e Oceania, adicionando treze novos territórios. O valor da negociação girou em torno de US\$273,3 milhões.

\section{As mídias sociais e o mundo segundo os brasileiros}

As mídias sociais são ferramentas imprescindíveis para qualquer tipo de comunicação do século XXI. A criação de novas tecnologias móveis e a disponibilidade da rede sem fio (wi-fi) em diversos lugares aumentou o alcance da comunicação e da interatividade. Segundo a pesquisa TIC Domicílios do Comitê Gestor de Internet (CGI)³, publicada em 2015, há no Brasil mais de 102 milhões de usuários de internet. Os dados foram coletados entre novembro de 2015 e julho de 2016. De acordo com o IBGE (2016), o país tem cerca de 206 milhões de habitantes, portanto $49,51 \%$ da população brasileira frequentemente estão conectados. A chegada da internet para o grande público na década 1990 e a consequente popularização na década seguinte fez com que as empresas se voltassem às novas ferramentas de comunicação. Anunciar nas mídias tradicionais, tais como televisão, rádio, jornal ou revista, contribui para alavancar o negócio de qualquer empresa, no entanto, os empresários perceberam que é necessário um contato mais próximo com o consumidor. As redes sociais deixaram de ser apenas uma rede destinada ao relacionamento e ao entretenimento, e sim, passaram a ser usadas para fazer negócio. Surge uma nova mídia e em tal contexto cabem as considerações de Goulart (2014) ao apontar as diferenças entre "redes sociais" e "mídias sociais":

\footnotetext{
[...] o termo "redes sociais" se destina mais especificamente, a denotar sistemas computacionais construídos para conectar as pessoas, permitindo troca de informações. [...] Já o termo "mídias sociais" se aplica, mais amplamente, aos sistemas computacionais baseados na Internet, destinados, fundamentalmente, ao estabelecimento e à manutenção dos relacionamentos entre seus usuários, pessoas ou organizações Além disso, inclui a produção de conteúdos e seu compartilhamento entre as pessoas "digitalmente" conectadas. (GOULART, 2014, p. 12)
}

Um consumidor valorizado se sente parte importante do processo. Essa aproximação entre o produtor e o consumidor faz com que as barreiras de comunicação sejam quebradas. Hoje em dia, é possível assistir ao programa favorito onde quer que se esteja, basta possuir um smartphone ou um tablet. E mais, os fãs podem interagir com os produtores, tanto para elogios quanto para críticas. Jenkins (2009) afirma que a internet impulsionou a convergência midiática, resultando em um processo de coexistência e

${ }^{2}$ CF: Agência de Notícias: PR Newswire: http://www.prnewswire.com/news-releases/warner-bros-television-group-fecha-acordo-para-adquirir-o-eyeworks-group-aumentando-o-negocio-de-producao-internacional-de-tv-244977227.html.

${ }^{3}$ CF: CF: CGI. Comitê Gestor da Internet no Brasill. TIC domicílios 2015. Pesquisa sobre o uso de Tecnologias de Informação e Comunicação nos Domicilios Brasileiros:http://cetic.br/pesquisa/domicilios/indicadores 
relacionamento de várias mídias. O autor afirma que,

Por convergência, refiro-me ao fluxo de conteúdos através de múltiplas plataformas de mídia, à cooperação entre múltiplos mercados midiáticos e ao comportamento migratório dos públicos dos meios de comunicação, que vão a quase qualquer parte em busca de experiências de entretenimento que desejam. (JENKINS, 2009, p. 29)

Os grandes conglomerados midiáticos desenvolveram um relacionamento entre as mídias. As tevês estão disponibilizando conteúdos em plataformas de vídeos, as rádios criaram web rádios para transmissão simultânea, e a mídia impressa também publica as matérias nos sites. Para Jenkins (2009, p. 43), os consumidores possuem mais liberdade de escolha e são mais interativos, provocando mudanças na relação - emissor e receptor -, pois: "a convergência das mídias altera a relação entre tecnologias existentes, indústrias, mercados, gêneros e públicos. A convergência altera a lógica pela qual a indústria midiática opera e pela qual os consumidores processam a notícia e o entretenimento". O consumidor escolhe como assistir a determinado produto, de uma forma que se adapte ao seu estilo de vida. Este é o conceito on demand. Benazzi e Nachamkes (2014, p. 1) entendem que "nesse contexto, a tecnologia de Video on Demand (VOD) oferece ao usuário a experiência de controlar os vídeos que serão assistidos e definir a programação de acordo com sua conveniência". Lima (2013, p. 35) também acredita que esta seja uma tendência, já que "os consumidores estão mais propensos a controlar a programação do que assistem e a decidir como e quando consumir os produtos disponíveis". Segundo Benazzi e Nachamkes (2014, p. 1) "a questão de que VOD é percebido como forma de lidar com o tempo, na forma prover conveniência no entretenimento".

Lipovestsky e Serroy (2011) afirmam que o surgimento das novas tecnologias modificou a sociedade em todos os campos, e isso influenciou em uma readaptação no modo de receber a informação: "A economia, a sociedade, a cultura, a vida cotidiana, todas as esferas são remodeladas pelas novas tecnologias da informação e da comunicação: a sociedade das telas é a da sociedade informacional" (LIPOVESTSKY; SERROY, 2011, p. 77). Nesse contexto a utilização das redes sociais para produzir ou consumir conteúdo, fortalece a relação entre consumidor e produtor, aproximando-os de tal forma que esse tipo de mídia passa a ser vista estrategicamente pelas instituições. Castells (2015) reconhece a importância estratégica dessa interação e mostra o quanto é importante se comunicar com o público-alvo através das postagens. Para o autor,

A comunicação online permite uma interação com o público inexistente em outras mídias. É possível analisar imediatamente os resultados de uma ação, identificar e modificar estratégias que não estão funcionando, enviar respostas em tempo real além de compartilhar e expor materiais facilmente (CASTELLS, 2015, p. 104).

De acordo com Castells (2015), a interação entre empresa e telespectador só terá sucesso se a empresa entender a cultura daquele ambiente. A falta de atualização atrapalha a comunicação e compromete a interação. A tecnologia existente é para ser usada de forma adequada para evitar ruídos que possam ocasionar a perda de seguidores, e assim comprometer o processo de comunicação, uma vez que

[...] o compartilhamento de significado por meio da troca de informação. O processo é definido pela tecnologia da comunicação pelas características dos emissores e 
Lipovestsky e Serroy (2011) esclarecem que a produção de conteúdo não é mais exclusividade de uma empresa midiática. Qualquer pessoa que tenha internet e computador pode ser um formador de opinião, seja profissionalmente, ou por hobby:

\begin{abstract}
[...] Passou-se das mídias emissoras às mídias interativas (blogs, fóruns comunitários, redes sociais), que permitem a indivíduos do mundo inteiro partilhar, discutir, divertir-se sem jamais ter se encontrado. Nessa galáxia comunicacional, todo mundo pode produzir conteúdo, cada um pode tornar-se fotógrafo, realizador de vídeo, até mesmo jornalista difundido informação com a web, os jornalistas profissionais perdem seu antigo monopólio, as fronteiras entre informação profissional e informação amadora tornam-se cada vez mais incertas e vagas (LIPOVESTSKY; SERROY, 2017, p. 78)
\end{abstract}

Todos os profissionais de comunicação podem e devem interagir com o seu público. Excluam-se os haters' e atente-se às opiniões construtivas para enxergar novas perspectivas e aproveitá-las caso seja interessante e viável. Lipovestsky e Serroy (2011) entendem que o mundo contemporâneo está conectado e as fronteiras da informação foram derrubadas. Para os autores,

\begin{abstract}
[...] A rede criou a teia - teia de tela e tela de aranha a uma só vez -, cujas ramificações se estendem aos mais extremos pontos do planeta, interconectando os homens uns aos outros, permitindo-thes conversar além dos continentes, mostrar-se e ver-se pelos blogs e pela webcam, criar, vender, trocar, até mesmo inventar para si uma "second life" (LIPOVESTSKY; SERROY, 2017, p. 76)
\end{abstract}

Fuchs (2014) descreve a comunicação como uma atividade social e que o ser humano não conseguiria viver sem comunicação. Para o autor, a comunicação está explícita no cotidiano de cada um, pois

\footnotetext{
[...] Se entendemos a atividade social como comunicação ou interação simbólica, então nem todo o uso da mídia é social. Com base nesta compreensão, não é social se você escrever um documento sozinho, mas é social para enviar um e-mail ou bate-papo com um amigo no Facebook. A comunicação é uma característica básica de todas as sociedades e de toda a atividade humana. Não podemos viver e sobreviver sem comunicação, assim como não podemos sobreviver sem comida e água. A comunicação ocorre rotineiramente na vida cotidiana. (FUCHS, 2014, p. 12) $)^{5}$
}

${ }^{4} \mathrm{O}$ termo haters é bastante utilizado na internet para classificar os internautas que postam mensagens de ódio com o objetivo de ofender ou constranger alguém.

5[... If we understand social activity to mean communication or symbolic interaction, then not all media use is social. Based on this understanding, it is not social if you write a document alone, but it is social to send an email or chat with a friend on Facebook. Communication is a basic feature of all societies and all human activity. We cannot live and survive without communication, just like we cannot survive without food and water. Communication takes place routinely in everyday life. (FUCHS, 2014, p.12) - Tradução nossa. 
As empresas que valorizam as mídias sociais e alocam profissionais para acompanhar e interagir nas plataformas mais utilizadas podem compreender melhor o mercado, e a partir dessas informações, readequar as diretrizes estratégicas. Fuchs (2014) diz que as empresas trabalham com as mídias sociais para conquistar relacionamento, conhecimento e reputação. Para o autor,

[...] Os usuários usam as mídias sociais porque buscam, até certo ponto, atingir o que Bourdieu (1986a, 1986b) denomina capital social (acumulação de relações sociais), capital cultural (acumulação de qualificação, educação, conhecimento) e capital simbólico (a acumulação de reputação). (FUCHS, 2014, p. 111) $^{6}$

De acordo com a Secretaria de Comunicação Social da Presidência da República7 (2015 apud CARDOZO; KUBO, 2016, p. 10), as mídias sociais e os programas de trocas de mensagens instantâneas mais usadas pelas pessoas são: Facebook 83\%; Whatsapp 58\%; YouTube 17\%; Instagram 12\%; Google+ 8\%; Twitter 5\%. Com 1,2 bilhão de usuários pelo mundo - 99 miIhões de usuários no Brasil - o Facebook é dividido entre o perfil pessoal e o perfil profissional, conhecido como Fanpage. É por meio das fanpages que a empresa cria um relacionamento com o cliente. Porto (2014, p. 12) ressalta a importância desse canal para o crescimento corporativo das empresas, já que a interação com os seguidores possibilita um entendimento maior de como está o produto no mercado, abrindo uma oportunidade de corrigir falhas e desenvolvê-lo melhor: "O Facebook oferece todos os recursos necessários para que sua empresa ou negócio utilize este canal expressivo para se comunicar com fãs ou clientes" (PORTO, 2014, p. 12).

A comunicação entre o emissor e receptor de um programa de infotenimento, onde a informação é tão importante quanto o entretenimento, precisa ser bastante explorada. As mídias sociais podem e devem ajudar nesse relacionamento, assim como o Facebook é a principal ferramenta de recrutamento de O Mundo Segundo os Brasileiros. De acordo com a coordenadora de produção da Eyeworks, Renata Figueira, durante entrevista ${ }^{8}$ concedida ao autor deste artigo, o processo de recrutamento dos participantes é feito através da fanpage do programa. Caso, não seja suficiente, a produtora faz uma pesquisa em blogs de expatriados e entra em contato com os consulados e outros órgãos oficiais: "Depois da escolha do destino, a gente sempre começa pelas redes sociais. Se a gente não tiver nenhum retorno, a gente vai até os consulados e os órgãos mais formais", esclarece Renata Figueira. A produtora então faz uma pré-seleção das pessoas antes de ir ao destino e usa como critério a dicção, fluência verbal, espontaneidade perante a câmera, e o mais importante, a disponibilidade para a gravação. Figueira deixa claro que a Eyeworks se preocupa em checar as informações históricas e tu-

6[...] Users employ social media because they strive for a certain degree to achieve what Bourdieu (1986a, 1986b) terms social capital (the accumulation of social relations), cultural capital (the accumulation of qualification, education, knowledge) and symbolic capital (the accumulation of reputation). (FUCHS, 2014, p. 111) - Tradução nossa

${ }^{7}$ CF: Secretaria da Comunicação Social. Pesquisa Brasileira de mídia 2015: hábitos de consumo de mídia pela população brasileira: http://www.secom.gov.br/atuacao/pesquisa/lista-de-pesquisas-quantitativas-e-qualitativas-de-contratos-atuais/pesquisa-brasileira-de-midia-pbm-2015.pdf 8Entrevista realizada no dia 13/05/2016 com Renata Figueira (Coordenadora de Produção da Eyeworks do Brasil). 
rísticas, no entanto, ela não checa as informações autobiográficas, já que é irrelevante para o desenvolvimento do programa.

A fanpage possui o mesmo nome do programa, e até o início de junho de 2017, a página indicava mais de 270 mil curtidas. Até julho de 2016, a página era constantemente atualizada, mas desde então visualizamos apenas sete postagens. Observamos os comentários da página, e verificamos que a produtora dedica-se apenas à divulgação dos episódios e ao recrutamento dos apresentadores. Muito pouco. Uma mídia repleta de comentários de fãs e telespectadores tem um grande potencial de fidelização. É de se lamentar que não haja uma interação adequada.

Além da Fanpage, a Eyeworks tem Instagram e Twitter oficiais. Estranhamente, a produtora não mantém um canal no YouTube. Inicialmente, achávamos que um canal encontrado fosse oficial, mas ao verificar dias depois que os episódios disponibilizados não podiam mais ser acessados, ficou evidente que ali era apenas um canal promovido por um fã. Ao expandir a pesquisa, encontramos outros canais relacionados ao programa. Estes também estavam proibidos de reproduzir. Sempre com a mesma mensagem: "Este vídeo apresenta conteúdo de Shed Media que o bloqueou". A Shed Media é um abrigo de mídia independente, que foi comprado pela Time Warner em 2010, conforme reportagem do "The Guardian (2010)". Ou seja, podemos afirmar que o conteúdo foi bloqueado a pedido do dono (Eyeworks/Warner Bros.) do produto. Uma oportunidade de melhorar a interação foi desperdiçada, já que os vídeos que sobem nessa plataforma podem ganhar comentários. A possibilidade de um contato mais próximo com o público foi perdida.

O Instagram não é atualizado desde 05 de agosto de 2016. A produtora publicava fotos do episódio que seria exibido, sempre complementado com informações relevantes, para o seguidor degustar e sentir vontade de assistir ao programa. Muitos comentários são postados, mas como é a praxe da produtora, nenhum deles é respondido. Mais uma plataforma importante que não é utilizada em seu máximo potencial. Já o Twitter era usado somente para a divulgação de exibição dos programas, mas depois de 26 de dezembro de 2015, essa mídia foi deixada de lado, mesmo tendo mais de 4000 seguidores. Embora a Eyeworks seja uma produtora que produza conteúdo moderno e de qualidade, ela ainda não está preocupada em se relacionar com o público-alvo, a não ser para divulgação dos episódios e recrutamento dos participantes. Desde agosto de 2016, as mídias sociais foram deixadas de lado, e a empresa não segue as tendências midiáticas e sociais.

\section{Considerações Finais}

A comunicação é uma atividade essencial de todas as sociedades. O ser humano é um ser social e sempre necessitará se relacionar com alguém. A socialização está presente em todos os lugares, inclusive nos artefatos tecnológicos que usamos. O surgimento das redes sociais estreitou o relacionamento entre produtores e consumidores. As mídias sociais são um novo fenômeno e as plataformas não só transformaram a comunicação pessoal, como também trouxeram um viés para a comunicação empresarial. Atualmente, é impensável para qualquer empresa, independentemente do ramo de negócios, não se relacionar com o seu público-alvo. Facebook/ Fanpage, Instagram, Twitter, YouTube, são algumas das plataformas mais apropriadas para um bom marketing de relacionamento. A produção do programa O Mundo Segundo os Brasileiros utiliza essas plataformas, exceto o YouTube, para facilitar a produção, diminuir os custos, ouvir sugestões e críticas, e criar fidelização do produto. Entretanto, essa 
comunicação vem deixando a desejar.

Em todas essas mídias, a produção da Eyeworks interage muito pouco com os telespectadores. A Fanpage é usada mais para recrutamento e divulgação. Os seguidores fazem perguntas e dão dicas, mas a Eyeworks não se preocupa em comentá-las ou respondê-las. 0 Twitter que só servia para divulgação de episódios está abandonado desde 26 de dezembro de 2015. O Instagram está desatualizado desde 05 de agosto de 2016. Essa plataforma contém vários comentários dos seguidores, mas em nenhum momento existe uma interação servindo apenas para a divulgação da exibição dos episódios.

Seria interessante para o programa que houvesse um canal oficial no YouTube, já que os vários canais mantidos pelos fãs não têm nenhuma obrigação com a verdade. Inclusive, nós pensávamos que um desses canais era oficial, e após perceber que alguns episódios estavam bloqueados, percebemos que a plataforma não tinha nenhum vínculo com a produtora. Em um programa de infotenimento, no qual a informação e o entretenimento caminham juntos, é importante a interatividade entre emissor e receptor. A Eyeworks produz um ótimo programa, mas peca na interação com os internautas. Um programa jovem e atraente como é O Mundo Segundo os Brasileiros, necessita ser mais bem trabalhado nas mídias sociais.

\section{Referências}

AGÊNCIA BRASIL. IBGE: Brasil já tem 206 milhões de habitantes. http://agenciabrasil.ebc com.br/geral/noticia/2016-08/ibge-brasil-ja-tem-206-milhoes-de-habitantes. Acessado em 05/12/2016

BENAZZI, J.R.D.S.C; NACHAMKES, K. O comportamento de consumo dos consumidores de video on demand. Comunicon 2014 (08 a 10 de outubro de 2014).

BRASIL, Presidência da República. Secretaria da Comunicação Social. Pesquisa Brasileira de mídia 2015: hábitos de consumo de mídia pela população brasileira. Brasília, Secom, 2014.

CASTElls, M. O Poder da Comunicação. São Paulo: Paz e Terra, 2015.

CARDOZO, C. G. G. e KUBO, S. D. Algoritmos e Facebook. Monografia de Pós Graduação em Assessoria de Comunicação e Mídias Sociais. Universidade Anhembi Morumbi, São Paulo, 2016.

CGI. COMITÊ GESTOR DA INTERNET NO BRASIL. TIC domicilios 2015. Pesquisa sobre o uso de Tecnologias de Informação e Comunicação nos Domicilios Brasileiros. São Paulo, 2016.

DEJAVITE, F. A. A noticia light e o jornalismo de infotenimento. Intercom - Sociedade Brasileira de Estudos Interdisciplinares da Comunicação - XXX Congresso Brasileiro de Ciências da Comunicação. Santos, 29 de agosto a 2 de setembro de 2007, pp. 2.

INFOtenimento: Informação + entretenimento no jornalismo. São Paulo: Paulinas, 2006.

FUCHS, C. Social media: a critical introduction. London: SAGE, 2014, pp. 9-35 e 98-124. 
GOMES, Itania Maria Mota. O Infotainment e a Cultura Televisiva. In: João Freire Fillho. (Org.). A TV em transição. Tendências de programação no Brasil e no mundo. 1 ed. Porto Alegre: Sulina, 2009

GOULART, E.E. Mídias Sociais: uma contribuição de análise. Porto Alegre: Edipucrs, 2014.

JENKINS, H. Cultura da Convergência. São Paulo: Aleph, 2009.

LIMA, I. Os Devoradores. Folha de S. Paulo, São Paulo, 24 set 2013. Caderno Ilustrada, p. 35.

LIPOVESTSKY, G. A cultura mundo: resposta a uma sociedade desorientada / Gilles Lipovestsky e Jean Serroy; tradução: Maria Lúcia Machado. São Paulo: Companhia das Letras, 2017.

MADEIRA, C. G.; GALLUCCI, L. Mídias Sociais, Redes Sociais e sua Importância para as Empresas no Início do Século XXI. Intercom - Sociedade Brasileira de Estudos Interdisciplinares da Comunicação XXXII Congresso Brasileiro de Ciências da Comunicação - Curitiba, PR - 4 a 7 de setembro de 2009 .

MARTINO, L. M. S. Teoria da comunicação: ideias, conceitos e métodos. Petrópolis: Vozes, 2009.

PINTO, A. V. O Conceito de Tecnologia. Rio de Janeiro: Contraponto, 2005.

PORTO, C. Facebook Marketing. Engajamento para transformar fãs em clientes. Ebook Ponto Conteúdo, São Paulo, 2014.

PORTAL ALLAN PERON. [Infográfico] Facebook Marketing - Dados de 2016 da Maior Rede Social do Mundo. http://www.allanperon.com.br/facebook-marketing/\#ixzz407xLKKWBV. Acessado em 25/10/2016.

PORTAL BAND. O Mundo Segundo os Brasileiros. http://entretenimento.band.uol.com.br/ omundosegundoosbrasileiros/. Acessado em 04/12/2016.

PORTAL BRASIL. Celulares superam computadores no acesso à internet. http://www.brasil. gov.br/infraestrutura/2016/04/pela-primeira-vez-celulares-superaram-computadores-no-acesso-a-internet-no-pais. Acessado em 25/10/2016.

PR NEWSWIRE. Warner Bros. Television Group fecha acordo para adquirir o Eyeworks Group aumentando o negócio de produção internacional de TV. http://www.prnewswire.com/ news-releases/warner-bros-television-group-fecha-acordo-para-adquirir-o-eyeworks-group-aumentando-o-negocio-de-producao-internacional-de-tv-244977227.html. Acessado em 04/12/2016

RANGEL, Patrícia. Globo Esporte SP. Ousadia e Experimentalismo na Produção da Informação-Entretenimento. Videre Futura, São Paulo, 2010. 
paradoresor

SACRAMENTO, W. Viagem na TV. uma análise sobre o programa "O Mundo Segundo os Brasileiros". In: BIEGING, P.; CHIARIONI, B. (org). Apreensões do cotidiano: por um olhar da comunicação. São Paulo: Pimenta Cultural, 2014

THE GUARDIAN. Time Warner buys Shed Media. https://www.theguardian.com/media/2010/ aug/05/independent-production-companies-television. Acessado em 04/12/2016.

YOUTUBE, O Mundo Segundo os Brasileiros. https://www.youtube.com/user/OMundo2osBrasileiros. Acessado em 25/10/2016.

Recebido: 02/04/2017 Aceito: 07/05/2019 